\title{
Toll-like Receptor (TLR) and Nucleotide-Binding Oligomerization Domain (NOD) Signaling during Vibrio cholerae Infection
}

\begin{abstract}
Cholera remains a significant health problem in developing countries due to its ability to spread rapidly and kills a high proportion of those affected. The disease is produced by Vibrio cholerae that colonizes in the human intestine and causes inflammatory diarrheal diseases. The reactogenicity of vaccine strain causes a serious problem in clinical settings. Besides the study of organisms V. cholerae, a thorough understanding of the host response following $V$. cholerae infection is indispensable to combat the disease from newly emerging threats. Elucidation of molecular mechanisms of V. cholerae induced inflammatory response through Toll-like receptor (TLR) and nucleotide-binding oligomerization domain (NOD) will eventually help to design proper vaccine or drugs for appropriate targets.
\end{abstract}

Keywords

Cholera; Vibrio cholerae; TLR; NOD; Cytokines; Inflammation; LPS; Cholera Toxin; Reactogenicity; Vaccine

\begin{abstract}
Mini Review
Volume 2 Issue 1 - 2015

Arunava Bandyopadhaya ${ }^{1 *}$ and Keya Chaudhuri $^{2}$

${ }^{1}$ Surgery Department, Massachusetts General Hospital \& Harvard Medical School, USA

${ }^{2}$ Molecular \& Human Genetics Division, Indian Institute of Chemical Biology, India

*Corresponding author: Arunava Bandyopadhaya, Surgery Department, Massachusetts General Hospital \& Harvard Medical School, Boston, USA, Tel: 1-617-724-

7814; Email: bandyopadhaya@molbio.mgh.harvard.edu

Received: December 30, 2014| Published: January 15, 2015
\end{abstract}

\section{Abbreviations}

TLR: Toll-Like Receptor; NOD: Nucleotide-Binding Oligomerization Domain; CT: Cholera Toxin; LPS: Lipo Polysaccharide; CARDs: Caspase Activating and Recruitment Domains; APCs: Antigen Presenting Cells; MAPK: Mitogen Activated Protein Kinase; NLR: Nod Like Receptor; PYDs: Pyrin Domains; OMV: Outer Membrane Vesicle

\section{Introduction}

Vibrio cholerae is a highly motile non-invasive Gram-negative organism which colonizes the small intestine and produces a potent enterotoxin called cholera toxin (CT)-a major virulence determinant that causes massive intestinal fluid loss leading to profuse watery diarrheal syndrome associated with $V$. cholerae infection [1,2]. There are more than 200 serogroups of $V$. cholerae recognized on the basis of their lipo polysaccharide (LPS) 0 side chain antigenic structures [3]. There are two serogroups of $V$. cholerae 01 and 0139 which can infect humans and cause epidemic and pandemic cholera. The serogroup V. cholerae 01 is subdivided into two biotypes, classical and El Tor depending on biochemical properties and phage sensitivity. Each biotype can be divided into three serotypes depending on expression of three O-antigens (A, B, and C): (1) Ogawa (A and B), (2) Inaba (A and C) and (3) Hikojima (A, B and C) $[4,5]$. The pathogenesis of cholera is a multi factorial process and involves several genes encoding virulence factors that aid the pathogen in its colonization, coordinated expression of virulence factors, and toxin action. The expression of virulence factors in $V$. cholerae is coordinately regulated by ToxR, an inner membrane protein which regulates the $\operatorname{ctx} A B$ structural gene and CT expression $[6,7]$. ToxR also regulates on which requires another Trans membrane transcriptional activator TcpP to synergistically activate the expression of ToxT $[8,9]$. ToxR acts as a master regulator and remains under the control of environmental factors [10]. ToxR directly regulates the expression of the outer membrane porin proteins OmpU and OmpT in a separate branch of the ToxR cascade independent of TcpP and ToxT $[11,12]$ which has been suggested to be involved in adherence during pathogenesis $[7,13]$. Toxinogenicity is predominating pathogenic factor, but colonization is clearly an essential step in disease progression. The organism must colonize the small bowel to release CT. No diarrhea is seen when volunteers are fed strains of $V$. cholerae, which is unable to colonize [14].

Cholera has traditionally considered as a non-inflammatory diarrheal disease but some evidence point towards an inflammatory component in the pathogenesis of the disease [1522] including increased infiltration of neutrophils, degranulation of mast cells and eosinophils, and production of some innate defense molecules during acute cholera patients [20-26]. Cholera patients are often treated with antimicrobials or antibiotics

Table1: Using of Antibiotics in cholera treatment.

\begin{tabular}{|c|}
\hline Antibiotics used for cholera treatment \\
\hline Doxycycline [119] \\
\hline Tetracycline [120] \\
\hline Ciprofloxacin [121] \\
\hline Azithromycin [122,123] \\
\hline Erythromycin [124] \\
\hline Chloramphenicol [125] \\
\hline Furazolidone [126] \\
\hline Sulfaguanidine [125] \\
\hline Orfloxacin [120] \\
\hline Trimethoprim- sulfamethoxazole [128] \\
\hline
\end{tabular}


$[27,28]$ (Table 1), but the growing trend of antibiotics resistance or poorly designed vaccines is craving the right component of vaccine development which could lead to the effective immunization. However, after elimination of several toxin genes, including the CT from vaccine wild-type strains, mild to moderate diarrhea is inevitable in volunteers [29-31]. The reactogenicity of vaccine strains in volunteer studies points towards the presence of some other component besides CT that can elicit a host response. The adaptive immunity against $V$. cholerae and CT has been investigated intensely for development of effective vaccine $[26,32,33]$. Little is known about the innate defense mechanisms during cholera that may be involved in the early defense against the infection and also in the initiation of the adaptive immune response. However, beyond the understanding of the mode of action of CT, we need an extensive knowledge regarding the response of the host to $V$. cholerae infection.

\section{V. cholerae Induced Inflammatory Response}

Cell culture models were initiated in hopes of developing an in vitro system for the study of host- $V$. cholerae communication and adherence. The interaction of the host with $V$. cholerae and other Vibrio species has been examined in a number of intestinal epithelial cells models like HT29-18N2, Caco-2, T84, HeLa and Int407 cells [34-37] and documented the release of pro inflammatory cytokines upon $V$. cholerae infection in intestinal epithelial cells [38]. Recently another experimental model using $\mathrm{H} 4$ cells- non transformed human fetal primary small intestinal epithelial cells provided preliminary evidence that CT induces an enhanced secretion mediated in part by a developmental upregulation of the cAMP response in immature versus mature human small intestine [39]. Rodriguez et al has shown that studies on delineating the factor responsible for reactogenicity of vaccine strains with the highly differentiated mucin-secreting cell line HT29-18N2 [40]. Once $V$. cholerae has been detected by epithelial cells, a number of signal transduction pathways are activated within the infected cells and initiate defensive responses by the host [37,41-46]. These signaling pathways usually result in the activation of nuclear factor kappa B (NF- $\mathrm{B}$ ) transcription factors important in driving expression of genes involved in the inflammatory response $[38,43,47]$. Certain $V$. cholerae strains as well as CT may stimulate a modest intestinal inflammatory response $[15,18,25]$. In a mouse pulmonary model of infection, Fullner et al. [48] have shown the evidence of inflammation including infiltration of polymorpho nuclear leukocytes (PMNs), tissue damage, localized release of tumor necrosis factor (TNF)- $\alpha$, interlukins (IL)- 6 and the neutrophil chemo attractant protein macrophage inflammatory proteins (MIP)-2 by accessory toxins of $V$. cholerae. Recently, $V$. cholerae mediated host inflammation is also scored in the neonatal mouse model [49]. Similarly, V. cholerae vaccine strains promote symptoms consistent with inflammation in human volunteers [50]. In altogether, these evidences suggest the existence of an inflammatory component in the diarrhea of clinical cholera. But, CT has shown immune deviating properties in macrophages $[51,52]$. However, little is known about the role of $V$. cholerae in initiating the innate inflammatory response and the potential contribution of individual $V$. cholerae components to cytokine induction through toll-like receptors (TLRs) and nucleotide-binding oligomerization domain (NODs) receptors.

\section{TLR and NOD Pathway}

Recognition and uptake of microbes are based on germ line-encoded pattern recognition receptors (PRRs) like Tolllike receptors (TLR) and nucleotide-binding oligomerization domain (NOD) receptors [53]. These receptors detect conserved microbial structures that are not found in the host. A common aim of the innate immunity is to rapidly detect and stop the spread of a pathogen. In contrast to the innate immunity, adaptive or acquired immunity is specific to foreign antigens. Adaptive immunity offers pathogen-specific detection and targeted immune response, which is usually effective also against those microbes that may evade innate immune responses. Moreover, the immunological memory offers rapid, specific and efficient immune response upon re infection. The development of adaptive immunity requires a complex co-operation between antigen presenting cells (APCs) (macrophages, dendritic cells, and B cells) and T lymphocytes [54-56].

TLRs play a crucial role in microbial recognition, induction of antimicrobial genes, cytokines, chemokines and the control of adaptive immune responses [57-59]. NOD (NOD1 and NOD2)-like receptors (NLRs) are a physically distinct family of intracellular PRRs, which is apparently in the context of microbial reorganization and the induction of inflammatory response [58,60,61]. TLRs and NODs are widely expressed in various cell types of the gastrointestinal mucosa and immune cells (monocytes/macrophages or dendritic cells) participating in host defense against microbes.

TLRs and NODs function initiate by following ways:

a) Recognition of molecular patterns expressed on pathogens

b) Activation of signaling pathways through cascade upon recognition of molecular patterns

c) Initiation of secretion of pro/anti-inflammatory cyto- and chemokines that control adaptive immune system

d) Induction of antimicrobial functions

\section{TLRs Signaling}

The TLRs were found to be essential for anti-fungal and antibacterial defense in the Drosophila innate immunity system [6264].

Mammalian TLRs are categorized by three common structural features:

a) A ligand binding extracellular domain with leucine rich repeats (LRR)

b) A short trans membrane region

c) A highly homologous cytoplasmic Toll/interleukin 1 receptor (TIR) domain initiates downstream signaling cascades $[65,66]$. 
TLRs have emerged as the first-line innate immune surveillance systems to detect the presence of foreign pathogens and activate the cytokine responses that occur during infection, and to a large extent, shape the whole of the inflammatory response with all its consequences, both beneficial and harmful To date, 11TLR homolog's have recognized and their Ligands are peptidoglycan [67], LPS [68], diacyl- or triacyl-lipopeptide [69], dsRNA [70], un methylated CpG DNA motifs [71], and flagellin [72].TLR Ligands could be a major focus of adjuvant research for modern vaccine combinations tailored to specific pathogens[73].

TLR signaling is activated by ligand binding, which initiates the dimerization or multimerization of TLRs. Subsequently, TIR-domain-containing adaptor molecules are recruited to the intracellular domain of TLRs. Until now, five adaptor molecules have been identified:

i. Myeloid differentiation factor 88 (MyD88)

ii. TIR-domain containing adaptor inducing IFN- $\beta$ (TRIF)

iii. TIR-domain containing adaptor protein (TIRAP)

iv. TRIF-related adaptor molecule (TRAM)

v. Sterile alpha and HEAT/Armadillo motif protein (SARM) [74].

The activation of downstream signaling is mediated by MyD88 and TRIF [75]. TLR signaling results in the activation and nuclear translocation of NF- $\kappa \mathrm{B}$, interferon regulatory factors (IRFs) and mitogen activated protein kinase (MAPK)-regulated transcription factors [66]. These transcription factors regulate the expression of pro-inflammatory cytokines, chemokines and IFNs.

\section{NODs Signaling}

Nod1 and Nod2, two cytosolic mammalian proteins, have been recognized as intracellular peptidoglycan receptors [76]. Both contains caspase activating and recruitment domains (CARDs) at their NH2-termini, a single CARD domain in Nod1 and two tandem CARD domains containing receptor-interacting proteins (Rip)2 in Nod2, followed by a nucleotide binding domain and a series of tandem LRRs. The interaction between Nod1 and Rip2 initiates CARD-CARD association. Rip2 binds to the IкB kinase (IKK) complex, which is the essential component in the pathway that leads to the activation of NF- $\mathrm{KB}$. Rip2 is also involved in the TLR-mediated activation of NF- $\kappa \mathrm{B}$, suggesting a convergence of the signal transduction pathways that are activated by TLRs and Nod1 [77]. Nod1 detects peptidoglycan from gram-negative bacteria, whereas Nod2 can detect peptidoglycan from both gram-negative and gram-positive bacteria [78,79]. Nod-like receptor (NLRP) protein scan form inflammasomes in activated cells through interaction of their pyrin domains (PYDs) with other pyrin-containing proteins, namely the adaptor ASC, which allows the formation of the inflammasome complex, recruiting and activating caspase- 1 , resulting in the processing of the potent inflammatory cytokines $[60,80]$.

Activation of TLR and NOD pathways by $V$. cholerae expressed molecular patterns LPS: LPS, one of the major components of the outer membrane of $V$. cholerae induces pro inflammatory cytokines through MyD88-dependent TLR4 signaling pathway in macrophages [81,82]. LPS could not activate the TLR4 signaling efficiently in epithelial cells [83] due to lack of CD14 and TLR4 on epithelial cells [84]. V. cholerae mediated pro inflammatory response is also attenuated in mice with mutation in TLR4 gene [85]. MsbB has functional lipid A acyltransferase which is prerequisite for transferring a 3-hydroxylaureate to the glucosamine disaccharide in $V$. cholerae LPS [86]. The under acylated LPS is generated in msbB mutant strain of $V$. cholerae which exhibits less endotoxicity due to reduced stimulation of TLR4 [87]. During the acute stage of $V$. cholerae infection, LPSTLR4 mediated inflammatory responses could be blocked by host derived LPLUNC1 [88]. V. cholerae phosphatidylserine decarboxylase (PSD) is capable of activating host innate immunity through TLR4 [89] and it could have potential application for vaccine adjuvant.

Outer membrane vesicle (OMV): $\mathrm{OMV}$, which is considered as an alternative vaccine candidate for cholera infection also contains a relative large amount of LPS, peptidoglycan and CT [90-93]. OMV interacts with epithelial cells and leads to inflammatory response [94]. TLR2 signaling pathway is activated by OMV of $V$. cholerae in human embryonic kidney cell line [88]. The quorum sensing regulator hapR regulates OMVs which might influence immune response through NOD1 and NOD2 pathway [95]. V. cholerae OMV activates pro inflammatory response through NOD1 pathway and promotes $\mathrm{T}$ cell polarization for adaptive immunity [94].

Flagellins: $V$. cholerae possesses a single polar flagellum which contains a flagellar core protein enclosed by a membrane sheath that appears to be contiguous with the outer membrane [96]. The flagellar filament itself is comprised of multiple flagellin subunits, which are highly related and conserved. The flagellin genes are organized in two unlinked chromosomal loci, flaAC and flaEDB [97]. The flaA gene is indispensable for assembly and function of the flagellum since a mutation in flaA but not in the remaining four flaBCDE genes, abolished flagella production and motility [97]. Motility of $V$. cholerae plays a crucial role in colonization of the bacteria to the small intestinal mucosa [98]. FlaA, FlaB and FlaD are recognized by the innate immune system through TLR5 and induces pro inflammatory cytokines through NF- $\kappa$ B and MAPK pathway $[47,99]$. The inflammation induced by flagellins could be a major determinant for the $V$. cholerae vaccine reactogenicity.

Outer membrane proteins (Omp): The outer membrane protects Gram-negative bacteria against a harsh environment. The embedded proteins are crtical to the bacterial cell, such as translocation of solute or protein, as well as signal transduction. Expression of the $0 \mathrm{mpU}$ outer membrane protein of $\mathrm{V}$. cholerae is positively regulated by master regulator ToxR $[11,100]$. OmpU has adhesive properties which could play an important role in the pathogenesis of cholera [13]. OmpU could potentially activates pro inflammatory response in epithelial cells $[43,46]$ and macrophages. However, pre-exposure of OmpU could potentially 
block the TLR4-LPS induced cytokines [101].

Accessory toxins: The main concern with non-CT-producing $V$. cholerae is that these strains are often sufficiently virulent to make them unsafe for use as live attenuated vaccines $[15,102,103]$. The actions of accessory toxins of $V$. cholerae are responsible for the increased inflammation and contribute to the reactogenicity of live attenuated vaccine strains $[29,85,104,105]$

$V$. cholerae Hemolysin (HlyA) is an extracellular membranedamaging and water-soluble cytolytic exotoxin with a molecular mass of $65 \mathrm{kDa}[4,106,107]$ which contains two contiguous lectin domains, a $\beta$-trefoil domain homologous to the galactosebinding site of ricin and a $\beta$-prism domain homologous to the carbohydrate-binding site of the plant lectin jacalin [108]. The $C$ terminus $\beta$-prism lectin domain, considered as the only functional sugar-binding site of HlyA, is susceptible to proteolytic deletion [109]. HlyA protein exhibits a dual effect on macrophage function. TLR4-Myd88 signaling is activated by $\beta$-prism lectin domain of HlyA whereas TLR2 signaling is up-regulated by HlyA cytolytic protein domain for continuity of macrophage activation [110]. It induces apoptosis independent of TLR signaling like most of the toxin [111] and activates the resting macrophages through TLR [110]. V. cholerae hemolysine plus NOD1/NOD2 ligand induces NLPR3 inflammasome regulated caspae1 activation through NF$\kappa \mathrm{B}$ pathway [112].

$V$. cholerae secreted cytolysin (VCC) is another $\beta$-barrel group pore forming toxin of $79 \mathrm{kDa}$ molecular mass. Under proteolytic activation it forms oligomers in the membrane bound stage only [113]. VCC acts as TLR2 Ligands in mast cells and activates adaptive immune response [114]. A recent study has demostaterd that VCC is recognized by the host epithelial cells/macrophages and induces pro inflammatory response through TLR2/TLR6 dependent signaling pathway [115].

The multifunctional-auto processing repeats-in-toxin (MARTX) bacterial protein toxins modulates the virulence Vibrio species and serve as delivery platforms for cytotoxic effect or domains. This family of toxins is defined by the presence of a cysteine protease domain (CPD), which proteolytically activates the $V$. cholerae MARTX toxin [116]. $V$. cholerae MARTX also induces NLRP3-dependent caspase-1 activation [112], but the detailed mechanism needs further investigation. These accessory toxins likely damage the cell membrane to transport the PAPMs into the cytosoland activates the inflammatory response in the infected sites through formation of inflammasome. $V$. cholerae accessory toxins induce inflammatory responses through the infection of intestinal cells, which do not express TLRs or are insensitive to TLR signals (TLR2/4) to evoke tissue damage that may promote bacterial colonization.

\section{Crosstalk Between Epithelial Cells And Immune Cells During $V$, cholerae Infection}

$V$. cholerae colonizes in the intestinal epithelial layer and is transcytosed by specialized micro folded (M) cells, which is responsible for mucosal immune response [117]. V. cholerae associated molecular patterns are recognized by the PRR in the intestinal epithelial cells and produces host defense molecules like cytokines and chemokines. The coordinated release of cytokines/chemokines by intestinal epithelial cells is crucial for activating intestinal mucosal inflammatory responses as well as mucosal innate and adaptive immune responses. $V$. cholerae or $V$. cholerae flagellin activated epithelial cells secretes intestinal dendritic cells (DCs) inducing chemokines and subsequently stimulates immature DC cells [118]. Therefore, DCs undergo maturation, which is associated with high surface expression of co-stimulatory molecules as well as different secreted immuno modulatory cytokines through MAPK and Signal Transducer and Activator of Transcription (STAT) pathway that drives the naïve T cells into T-helper (Th) 1 or 2 cells [118]. A recent study has shown that V. cholerae produced OMV also activates DCs and primes a distinct population of $\mathrm{CD} 4+\mathrm{T}$ cells that secrete IL-17 [94]. In addition to Th1 or Th2 cells, DCs have also been implicated in the promotion of Th17 cells. Therefore, epithelial cells secreted inflammatory cytokines induce complex crosstalk between epithelial cells and immune cells and promote the pro inflammatory response by polarizing Th2/Th17 response during acute stage of cholera $[26,94,118]$. To understand the reactogenicity vaccine strain, it is necessary to address the involvement of TLRs/NODs and V. cholerae associated molecular patterns in crosstalk between epithelial cells and immune cells.

\section{Conclusion}

$V$. cholerae coordinates the regulation of virulence gene functions and modulates the host innate immune response during the acute stage of infection. The progression of the diseases is extremely complex and multi factorial in nature. The recent studies demonstrate that $V$. cholerae induces nuclear responses through signal transduction pathway and subsequently activation of pro inflammatory cytokines modulated by $V$. cholerae secretary factors, virulence and motility may explain some of its reacotogenic mechanisms. Reactogenicity is a major concern with $V$. cholerae vaccine in the present scenario. Therefore, deletion of the accessory toxins and flagellin genes from the vaccine strain could be a way to develop the live attenuated vaccine for $V$. cholerae as well as other enteric pathogens. However, there is a significant gap in understanding the $V$. cholerae mediated inflammation through TLR or NOD pathways which needs further investigation. The interaction of $V$. cholerae expressed factors with TLR/NOD could be an emerging field in mucosal innate immunity and the future studies revealing the role of PAMPs in $V$. cholerae pathogenesis will be helpful to generate safe, live-attenuated and non-reacotogenic $V$. cholerae vaccine strain.

\section{References}

1. Charles RC, Ryan ET (2011) Cholera in the 21st century. Curr Opin Infect Dis 24(5): 472-477.

2. Harris JB, LaRocque RC, Qadri F, Ryan ET, Calderwood SB (2012) Cholera. Lancet 379(9835): 2466-2476.

3. Mooi FR, Bik EM (1997) The evolution of epidemic Vibrio cholerae strains. Trends Microbiol 5(4): 161-165.

4. Kaper JB, Morris JG, Levine MM (1995) Cholera. Clin Microbiol Rev 
8(1): 48-86.

5. Mandal S, Mandal MD, Pal NK (2011) Cholera: a great global concern. Asian Pac J Trop Med 4(7): 573-580.

6. Miller VL, Mekalanos JJ (1984) Synthesis of cholera toxin is positively regulated at the transcriptional level by toxR. Proc Natl Acad Sci U S A 81(11): 3471-3475.

7. Childers BM, Klose KE (2007) Regulation of virulence in Vibrio cholerae: the ToxR regulon. Future Microbiol 2(3): 335-344.

8. Hase CC, Mekalanos JJ (1998) TcpP protein is a positive regulator of virulence gene expression in Vibrio cholerae. Proc Natl Acad Sci U S A 95(2): 730-734.

9. Higgins DE, Nazareno E, DiRita VJ (1992) The virulence gene activator ToxT from Vibrio cholerae is a member of the AraC family of transcriptional activators. J Bacteriol 174(21): 6974-6980.

10.Weber GG, Klose KE (2011) The complexity of ToxT-dependent transcription in Vibrio cholerae. Indian J Med Res 133: 201-206.

11. Miller VL, Mekalanos JJ (1988) A novel suicide vector and its use in construction of insertion mutations: osmoregulation of outer membrane proteins and virulence determinants in Vibrio cholerae requires toxR. J Bacteriol 170(6): 2575-2583.

12. Morgan SJ, Felek S, Gadwal S, Koropatkin NM, Perry JW, et al. (2011) The two faces of ToxR: activator of ompU, co-regulator of toxT in Vibrio cholerae. Mol Microbiol 81(1): 113-128.

13. Sperandio V, Giron JA, Silveira WD, Kaper JB (1995) The OmpU outer membrane protein, a potential adherence factor of Vibrio cholerae. Infect Immun 63(11): 4433-4438.

14. Levine MM, Black RE, Clements ML, Cisneros L, Saah A, et al. (1982) The pathogenicity of nonenterotoxigenic Vibrio cholerae serogroup 01 biotype El Tor isolated from sewage water in Brazil. J Infect Dis 145(3): 296-299.

15. Silva TM, Schleupner MA, Tacket CO, Steiner TS, Kaper JB, et al. (1996) New evidence for an inflammatory component in diarrhea caused by selected new, live attenuated cholera vaccines and by El Tor and Q139 Vibrio cholerae. Infect Immun 64(6): 2362-2364.

16. Speelman P, Rabbani GH, Bukhave K, Rask-Madsen J (1985) Increased jejunal prostaglandin E2 concentrations in patients with acute cholera. Gut 26(2): 188-193.

17. Mathan MM, Chandy G, Mathan VI (1995) Ultrastructural changes in the upper small intestinal mucosa in patients with cholera. Gastroenterology 109(2): 422-430.

18. Saha DR, Niyogi SK, Nair GB, Manna B, Bhattacharya SK (2000) Detection of faecal leucocytes \& erythrocytes from stools of cholera patients suggesting an evidence of an inflammatory response in cholera. Indian J Med Res 112: 5-8.

19. Rabbani GH, Islam S, Chowdhury AK, Mitra AK, Miller MJ, et al. (2001) Increased nitrite and nitrate concentrations in sera and urine of patients with cholera or shigellosis. Am J Gastroenterol 96(2): 467472 .

20. Kuchta A, Rahman T, Sennott EL, Bhuyian TR, Uddin T, et al. (2011) Vibrio cholerae 01 infection induces proinflammatory CD4+ T-cell responses in blood and intestinal mucosa of infected humans. Clin Vaccine Immunol 18(8): 1371-1377.

21. Rajpara N, Vinothkumar K, Mohanty P, Singh AK, Singh R, et al. (2013) Synergistic effect of various virulence factors leading to high toxicity of environmental $V$. cholerae non-01/ non-0139 isolates lacking ctx gene : comparative study with clinical strains. PLoS One 8(9): 0076200

22. Ellis CN, LaRocque RC, Uddin T, Krastins B, Mayo-Smith L, et al. (2015) Comparative proteomic analysis reveals activation of mucosal innate immune signaling pathways during cholera. Infect Immun 0276502814 .

23. Pastore G, Schiraldi G, Fera G, Sforza E, Schiraldi O (1976) A bioptic study of gastrointestinal mucosa in cholera patients during an epidemic in southern Italy. Am J Dig Dis 21(8): 613-617.

24. Gangarosa EF, Beisel WR, Benyajati C, Sprinz H, Piyaratn P (1960) The nature of the gastrointestinal lesion in asiatic cholera and its relation to pathogenesis: a biopsy study. Am J Trop Med Hyg 9: 125-135.

25. Qadri F, Raqib R, Ahmed F, Rahman T, Wenneras C, et al. (2002) Increased levels of inflammatory mediators in children and adults infected with Vibrio cholerae 01 and 0139. Clin Diagn Lab Immunol 9(2): 221-229.

26. Bhuiyan TR, Lundin SB, Khan AI, Lundgren A, Harris JB, et al. (2009) Cholera caused by Vibrio cholerae 01 induces T-cell responses in the circulation. Infect Immun 77(5): 1888-1893.

27. Ghosh A, Ramamurthy $\mathrm{T}$ (2011) Antimicrobials \& cholera: are we stranded? Indian J Med Res 133: 225-231.

28. Leibovici-Weissman Y, Neuberger A, Bitterman R, Sinclair D, Salam MA, et al. (2014) Antimicrobial drugs for treating cholera. Cochrane Database Syst Rev 6: CD008625.

29. Tacket CO, Losonsky G, Nataro JP, Cryz SJ, Edelman R, et al. (1993) Safety and immunogenicity of live oral cholera vaccine candidate CVD 110, a delta ctxA delta zot delta ace derivative of El Tor Ogawa Vibrio cholerae. J Infect Dis 168(6): 1536-1540.

30. Bubshait SA, Al-Turki K, Qadri MH, Fontaine RE, Cameron D (2000) Seasonal, nontoxigenic Vibrio cholerae 01 Ogawa infections in the Eastern Region of Saudi Arabia. Int J Infect Dis 4(4): 198-202.

31. Shirley DA, McArthur MA (2011) The utility of human challenge studies in vaccine development: lessons learned from cholera. Vaccine (Auckl) 2011(1): 3-13.

32. Holmgren JJ M, Svennerholm AM (1997) New and improved vaccines against cholera. In: Levine MMW (eds.), New Generation Vaccines. New York: Marcel Dekker. pp. 459-468.

33. Jayasekera CR, Harris JB, Bhuiyan S, Chowdhury F, Khan AI, et al. (2008) Cholera toxin-specific memory B cell responses are induced in patients with dehydrating diarrhea caused by Vibrio cholerae 01. J Infect Dis 198(7): 1055-1061.

34. Panigrahi P, Tall BD, Russell RG, Detolla LJ, Morris JG (1990) Development of an in vitro model for study of non-01 Vibrio cholerae virulence using Caco-2 cells. Infect Immun 58(10): 3415-3424.

35. Basu I, Mitra R, Saha PK, Ghosh AN, Bhattacharya J, et al. (1999) Morphological and cytoskeletal changes caused by non-membrane damaging cytotoxin of Vibrio cholerae on int 407 and HeLa cells. FEMS Microbiol Lett 179(2): 255-263.

36. Benitez JA, Spelbrink RG, Silva A, Phillips TE, Stanley CM, et al. (1997) Adherence of Vibrio cholerae to cultured differentiated human intestinal cells: an in vitro colonization model. Infect Immun 65(8): 3474-3477.

37. Stokes NR, Zhou X, Meltzer SJ, Kaper JB (2004) Transcriptional responses of intestinal epithelial cells to infection with Vibrio cholerae. Infect Immun 72(7): 4240-4248. 
38. Bandyopadhaya A, Sarkar M, Chaudhuri K (2007) Transcriptional upregulation of inflammatory cytokines in human intestinal epithelial cells following Vibrio cholerae infection. FEBS J 274(17): 4631-4642.

39. Lu L, Baldeon ME, Savidge T, Pothoulakis C, Walker WA (2003) Development of microbial-human enterocyte interaction: cholera toxin. Pediatr Res 54(2): 212-218.

40. Rodriguez BL, Rojas A, Campos J, Ledon T, Valle E, et al. (2001) Differential interleukin-8 response of intestinal epithelial cell line to reactogenic and nonreactogenic candidate vaccine strains of Vibrio cholerae. Infect Immun 69(1): 613-616.

41. Zhou X, Gao DQ, Michalski J, Benitez JA, Kaper JB (2004) Induction of interleukin-8 in T84 cells by Vibrio cholerae. Infect Immun 72(1): 389397.

42. Sarkar M, Chaudhuri K (2004) Association of adherence and motility in interleukin 8 induction in human intestinal epithelial cells by Vibrio cholerae. Microbes Infect 6(7): 676-685.

43. Bandyopadhaya A, Sarkar M, Chaudhuri K (2007) Human intestinal epithelial cell cytokine mRNA responses mediated by NF-kappaB are modulated by the motility and adhesion process of Vibrio cholerae. Int J Biochem Cell Biol 39(10): 1863-1876.

44. Bandyopadhaya A, Das D, Chaudhuri K (2009) Involvement of intracellular signaling cascades in inflammatory responses in human intestinal epithelial cells following Vibrio cholerae infection. Mol Immunol 46(6): 1129-1139.

45. Bandyopadhaya A, Bhowmick S, Chaudhuri K (2009) Activation of proinflammatory response in human intestinal epithelial cells following Vibrio cholerae infection through PI3K/Akt pathway. Can J Microbiol 55(11): 1310-1318.

46. Sarkar M, Bhowmick S, Casola A, Chaudhuri K (2012) Interleukin-8 gene regulation in epithelial cells by Vibrio cholerae: role of multiple promoter elements, adherence and motility of bacteria and host MAPKs. Febs J 279(8): 1464-1473.

47. Bandyopadhaya A, Sarkar M, Chaudhuri K (2008) IL-1beta expression in Int407 is induced by flagellin of Vibrio cholerae through TLR5 mediated pathway. Microb Pathog 44(6): 524-536.

48. Fullner KJ, Boucher JC, Hanes MA, Haines GK, Meehan BM, et al. (2002) The contribution of accessory toxins of Vibrio cholerae $01 \mathrm{El}$ Tor to the proinflammatory response in a murine pulmonary cholera model J Exp Med 195(11): 1455-1462.

49. Bishop AL, Patimalla B, Camilli A (2014) Vibrio cholerae-induced inflammation in the neonatal mouse cholera model. Infect Immun 82(6): 2434-2447.

50. Levine MM, Kaper JB, Herrington D, Losonsky G, Morris JG, et al. (1988) Volunteer studies of deletion mutants of Vibrio cholerae 01 prepared by recombinant techniques. Infect Immun 56(1): 161-167.

51. Satchell KJ (2003) Activation and suppression of the proinflammatory immune response by Vibrio cholerae toxins. Microbes Infect 5(13): 1241-1247

52. Veglia F, Sciaraffia E, Riccomi A, Pinto D, Negri DR, et al. (2011) Cholera toxin impairs the differentiation of monocytes into dendritic cells, inducing professional antigen-presenting myeloid cells. Infect Immun 79(3): 1300-1310.

53. Broz P, Monack DM (2013) Newly described pattern recognition receptors team up against intracellular pathogens. Nat Rev Immunol 13(8): 551-565.

54. MacLeod H, Wetzler LM (2007) T cell activation by TLRs: a role for
TLRs in the adaptive immune response. Sci STKE 2007(402): 48

55. Barr TA, Brown S, Ryan G, Zhao J, Gray D (2007) TLR-mediated stimulation of APC: Distinct cytokine responses of B cells and dendritic cells. Eur J Immunol 37(11): 3040-3053.

56. Annunziato F, Romagnani C, Romagnani S (2014) The 3 major types of innate and adaptive cell-mediated effector immunity. J Allergy Clin Immunol 0091-6749(14): 01585-01591

57. Medzhitov R (2001) Toll-like receptors and innate immunity. Nat Rev Immunol 1(2): 135-145.

58. Philpott DJ, Girardin SE (2004) The role of Toll-like receptors and Nod proteins in bacterial infection. Mol Immunol 41(11): 1099-1108.

59. Kawai T, Akira S (2011) Toll-like receptors and their crosstalk with other innate receptors in infection and immunity. Immunity 34(5): 637-650.

60. Chen G, Shaw MH, Kim YG, Nunez G (2009) NOD-like receptors: role in innate immunity and inflammatory disease. Annu Rev Pathol 4: 365398.

61. Caruso R, Warner N, Inohara N, Nunez G (2014) NOD1 and NOD2: Signaling, Host Defense, and Inflammatory Disease. Immunity 41(6): 898-908.

62. Williams MJ, Rodriguez A, Kimbrell DA, Eldon ED (1997) The 18-wheeler mutation reveals complex antibacterial gene regulation in Drosophila host defense. EMBO J 16(20): 6120-6130.

63. Liew FY, Xu D, Brint EK, O’Neill LA (2005) Negative regulation of tolllike receptor-mediated immune responses. Nat Rev Immunol 5(6): 446-458.

64. Narayanan KB, Park HH (2015) Toll/interleukin-1 receptor (TIR) domain-mediated cellular signaling pathways. Apoptosis.

65. Xu Y, Tao X, Shen B, Horng T, Medzhitov R, et al. (2000) Structural basis for signal transduction by the Toll/interleukin-1 receptor domains. Nature 408(6808): 111-115.

66. O’Neill LA, Golenbock D, Bowie AG (2013) The history of Toll-like receptors - redefining innate immunity. Nat Rev Immunol 13(6): 453 460

67. Dziarski R (2003) Recognition of bacterial peptidoglycan by the innate immune system. Cell Mol Life Sci 60(9): 1793-1804.

68. Alexander C, Rietschel ET (2001) Bacterial lipopolysaccharides and innate immunity. J Endotoxin Res 7(3): 167-202.

69. Buwitt-Beckmann U, Heine H, Wiesmuller KH, Jung G, Brock R, et al. (2006) TLR1- and TLR6-independent recognition of bacterial lipopeptides. J Biol Chem 281(14): 9049-9057.

70. Prehaud C, Megret F, Lafage M, Lafon M (2005) Virus infection switches TLR-3-positive human neurons to become strong producers of beta interferon. J Virol 79(20): 12893-12904.

71. Bauer S, Kirschning CJ, Hacker H, Redecke V, Hausmann S, et al. (2001) Human TLR9 confers responsiveness to bacterial DNA via speciesspecific CpG motif recognition. Proc Natl Acad Sci U S A 98(16): $9237-$ 9242.

72. Hayashi F, Smith KD, Ozinsky A, Hawn TR, Yi EC, et al. (2001) The innate immune response to bacterial flagellin is mediated by Toll-like receptor 5. Nature 410(6832): 1099-1103.

73. Steinhagen F, Kinjo T, Bode C, Klinman DM (2011) TLR-based immune adjuvants. Vaccine 29(17): 3341-3355. 
74. Takeda K, Akira S (2005) Toll-like receptors in innate immunity. Int Immunol 17(1): 1-14.

75. Akira S, Takeda K (2004) Toll-like receptor signalling. Nat Rev Immunol 4(7): 499-511.

76. Oviedo-Boyso J, Bravo-Patino A, Baizabal-Aguirre VM (2014) Collaborative Action of Toll-Like and Nod-Like Receptors as Modulators of the Inflammatory Response to Pathogenic Bacteria. Mediators Inflamm 2014: 432785

77. Kobayashi K, Inohara N, Hernandez LD, Galan JE, Nunez G, et al. (2002) RICK/Rip2/CARDIAK mediates signalling for receptors of the innate and adaptive immune systems. Nature 416(6877): 194-199.

78. Chamaillard M, Girardin SE, Viala J, Philpott DJ (2003) Nods, Nalps and Naip: intracellular regulators of bacterial-induced inflammation. Cell Microbiol 5(9): 581-592.

79. Inohara N, Nunez G (2003) NODs: intracellular proteins involved in inflammation and apoptosis. Nat Rev Immunol 3(5): 371-382.

80.Werts C, Rubino S, Ling A, Girardin SE, Philpott DJ (2011) Nod-like receptors in intestinal homeostasis, inflammation, and cancer. J Leukoc Biol 90(3): 471-482.

81. Miller SI, Ernst RK, Bader MW (2005) LPS, TLR4 and infectious disease diversity. Nat Rev Microbiol 3(1): 36-46.

82.Zughaier SM, Zimmer SM, Datta A, Carlson RW, Stephens DS (2005) Differential induction of the toll-like receptor 4-MyD88-dependent and -independent signaling pathways by endotoxins. Infect Immun 73(11): 2940-2950.

83. Backhed F, Meijer L, Normark S, Richter-Dahlfors A (2002) TLR4dependent recognition of lipopolysaccharide by epithelial cells requires sCD14. Cell Microbiol 4(8): 493-501.

84. Naumann M, Wessler S, Bartsch C, Wieland B, Meyer TF (1997) Neisseria gonorrhoeae epithelial cell interaction leads to the activation of the transcription factors nuclear factor kappaB and activator protein 1 and the induction of inflammatory cytokines. J Exp Med 186(2): 247-258.

85. Haines GK, Sayed BA, Rohrer MS, Olivier V, Satchell KJ (2005) Role of toll-like receptor 4 in the proinflammatory response to Vibrio cholerae $01 \mathrm{El}$ tor strains deficient in production of cholera toxin and accessory toxins. Infect Immun 73(9): 6157-6164.

86. Hankins JV, Madsen JA, Giles DK, Childers BM, Klose KE, et al. (2011) Elucidation of a novel Vibrio cholerae lipid A secondary hydroxyacyltransferase and its role in innate immune recognition. Mol Microbiol 81(5): 1313-1329.

87. Leitner DR, Feichter S, Schild-Prufert K, Rechberger GN, Reidl J, et al. (2013) Lipopolysaccharide modifications of a cholera vaccine candidate based on outer membrane vesicles reduce endotoxicity and reveal the major protective antigen. Infect Immun 81(7): 2379-2393.

88. Shin OS, Uddin T, Citorik R, Wang JP, Della Pelle P, et al. (2011) LPLUNC1 modulates innate immune responses to Vibrio cholerae. J Infect Dis 204(9): 1349-1357.

89. Thanawastien A, Montor WR, Labaer J, Mekalanos JJ, Yoon SS (2009) Vibrio cholerae proteome-wide screen for immunostimulatory proteins identifies phosphatidylserine decarboxylase as a novel Tolllike receptor 4 agonist. PLoS Pathog 5(8): 1000556.

90. Ellis TN, Kuehn MJ (2010) Virulence and immunomodulatory roles of bacterial outer membrane vesicles. Microbiol Mol Biol Rev 74(1): 81-94.
91. Kulp A, Kuehn MJ (2010) Biological functions and biogenesis of secreted bacterial outer membrane vesicles. Annu Rev Microbiol 64: 163-184.

92. Schild S, Nelson EJ, Bishop AL, Camilli A (2009) Characterization of Vibrio cholerae outer membrane vesicles as a candidate vaccine for cholera. Infect Immun 77(1): 472-484.

93. Chatterjee D, Chaudhuri K (2011) Association of cholera toxin with Vibrio cholerae outer membrane vesicles which are internalized by human intestinal epithelial cells. FEBS Lett 585(9): 1357-1362.

94. Chatterjee D, Chaudhuri K (2013) Vibrio cholerae 0395 outer membrane vesicles modulate intestinal epithelial cells in a NOD1 protein-dependent manner and induce dendritic cell-mediated Th2/ Th17 cell responses. J Biol Chem 288(6): 4299-4309.

95. Bielig H, Rompikuntal PK, Dongre M, Zurek B, Lindmark B, et al. (2011) NOD-like receptor activation by outer membrane vesicles from Vibrio cholerae non-01 non-0139 strains is modulated by the quorumsensing regulator HapR. Infect Immun 79(4): 1418-1427.

96. Sinha VB, Jacob A, Srivastava R, Kaper JB, Srivastava BS (1993) Identification of the flagellar antigens of Vibrio cholerae El Tor and their role in protection. Vaccine 11(3): 372-375.

97. Klose KE, Mekalanos JJ (1998) Differential regulation of multiple flagellins in Vibrio cholerae. J Bacteriol 180(2): 303-316.

98. Butler SM, Camilli A (2005) Going against the grain: chemotaxis and infection in Vibrio cholerae. Nat Rev Microbiol 3(8): 611-620.

99. Harrison LM, Rallabhandi P, Michalski J, Zhou X, Steyert SR, et al. (2008) Vibrio cholerae flagellins induce Toll-like receptor 5-mediated interleukin-8 production through mitogen-activated protein kinase and NF-kappaB activation. Infect Immun 76(12): 5524-5534.

100. Provenzano D, Lauriano CM, Klose KE (2001) Characterization of the role of the ToxR-modulated outer membrane porins OmpU and OmpT in Vibrio cholerae virulence. J Bacteriol 183(12): 3652-3662.

101. Sakharwade SC, Sharma PK, Mukhopadhaya A (2013) Vibrio cholerae porin OmpU induces pro-inflammatory responses, but down-regulates LPS-mediated effects in RAW 264.7, THP-1 and human PBMCs. PLoS One 8(9): 76583.

102. Coster TS, Killeen KP, Waldor MK, Beattie DT, Spriggs DR, et al. (1995) Safety, immunogenicity, and efficacy of live attenuated Vibrio cholerae 0139 vaccine prototype. Lancet 345(8955): 949-952.

103. Levine MM, Kaper JB, Black RE, Clements ML (1983) New knowledge on pathogenesis of bacterial enteric infections as applied to vaccine development. Microbiol Rev 47(4): 510-550.

104. Taylor DN, Killeen KP, Hack DC, Kenner JR, Coster TS, et al. (1994) Development of a live, oral, attenuated vaccine against El Tor cholera. J Infect Dis 170(6): 1518-1523.

105. Benitez JA, Garcia L, Silva A, Garcia H, Fando R, et al. (1999) Preliminary assessment of the safety and immunogenicity of a new CTXPhi-negative, hemagglutinin/protease-defective El Tor strain as a cholera vaccine candidate. Infect Immun 67(2): 539-545.

106. Ichinose $\mathrm{Y}$, Yamamoto $\mathrm{K}$, Nakasone N, Tanabe MJ, Takeda T, et al. (1987) Enterotoxicity of El Tor-like hemolysin of non-01 Vibrio cholerae. Infect Immun 55(5): 1090-1093.

107. Yamamoto K, Al-Omani M, Honda T, Takeda $\mathrm{Y}$, Miwatani $\mathrm{T}$ (1984) Non-01 Vibrio cholerae hemolysin: purification, partial characterization, and immunological relatedness to El Tor hemolysin. Infect Immun 45(1): 192-196. 
108. Olson R, Gouaux E (2005) Crystal structure of the Vibrio cholerae cytolysin (VCC) pro-toxin and its assembly into a heptameric transmembrane pore. J Mol Biol 350(5): 997-1016.

109. Dutta S, Mazumdar B, Banerjee KK, Ghosh AN (2010) Threedimensional structure of different functional forms of the Vibrio cholerae hemolysin oligomer: a cryo-electron microscopic study. J Bacteriol 192(1): 169-178.

110. Chakraborty DC, Mukherjee G, Banerjee P, Banerjee KK, Biswas T (2011) Hemolysin induces Toll-like receptor (TLR)-independent apoptosis and multiple TLR-associated parallel activation of macrophages. J Biol Chem 286(40): 34542-34551.

111. Fiorentini C, Falzano L, Travaglione S, Fabbri A (2003) Hijacking Rho GTPases by protein toxins and apoptosis: molecular strategies of pathogenic bacteria. Cell Death Differ 10(2): 147-152.

112. Toma C, Higa N, Koizumi Y, Nakasone N, Ogura Y, et al. (2010) Pathogenic Vibrio activate NLRP3 inflammasome via cytotoxins and TLR/nucleotide-binding oligomerization domain-mediated NFkappa B signaling. J Immunol 184(9): 5287-5297.

113. Alm RA, Stroeher UH, Manning PA (1988) Extracellular proteins of Vibrio cholerae: nucleotide sequence of the structural gene (hlyA) for the haemolysin of the haemolytic El Tor strain 017 and characterization of the hlyA mutation in the non-haemolytic classical strain 569B. Mol Microbiol 2(4): 481-488.

114. Arcidiacono D, Odom S, Frossi B, Rivera J, Paccani SR, et al. (2008) The Vibrio cholerae cytolysin promotes activation of mast cell (T helper 2) cytokine production. Cell Microbiol 10(4): 899-907.

115. Khilwani B, Mukhopadhaya A, Chattopadhyay K (2014) Transmembrane Oligomeric form of Vibrio cholerae Cytolysin Triggers TLR2/TLR6-dependent Pro-inflammatory Responses in Monocytes and Macrophages. Biochem J.

116. Satchell KJ (2007) MARTX, multifunctional autoprocessing repeatsin-toxin toxins. Infect Immun 75(11): 5079-5084.

117. Blanco LP, Dirita VJ (2006) Antibodies enhance interaction of Vibrio cholerae with intestinal M-like cells. Infect Immun 74(12): 69576964.

118. Bhowmick S, Chatterjee D, Chaudhuri K (2012) Human epithelial cells stimulated with Vibrio cholerae produce thymic stromal lymphopoietin and promote dendritic cell-mediated inflammatory Th2 response. Int J Biochem Cell Biol 44(11): 1779-1790.

119. De S, Chaudhuri A, Dutta P, Dutta D, De SP, et al. (1976) Doxycycline in the treatment of cholera. Bull World Health Organ 54(2): 177-179.

120. Greenough WB, Gordon RS, Rosenberg IS, Davies BI, Benenson AS (1964) Tetracycline in the Treatment of Cholera. Lancet 283(7329): 355-357.

121. Khan WA, Bennish ML, Seas C, Khan EH, Ronan A, et al. (1996) Randomised controlled comparison of single-dose ciprofloxacin and doxycycline for cholera caused by Vibrio cholerae 01 or 0139 . Lancet 348(9023): 296-300.

122. Khan WA, Saha D, Rahman A, Salam MA, Bogaerts J, et al. (2002) Comparison of single-dose azithromycin and 12-dose, 3-day erythromycin for childhood cholera: a randomised, double-blind trial. Lancet 360(9347): 1722-1727.

123. Saha D, Karim MM, Khan WA, Ahmed S, Salam MA, et al. (2006) Single-dose azithromycin for the treatment of cholera in adults. N Engl J Med 354(23): 2452-2462.

124. Burans JP, Podgore J, Mansour MM, Farah AH, Abbas S, et al. (1989) Comparative trial of erythromycin and sulphatrimethoprim in the treatment of tetracycline-resistant Vibrio cholerae 01. Trans R Soc Trop Med Hyg 83(6): 836-838.

125. Wallace CK, Anderson PN, Brown TC, Khanra SR, Lewis GW, et al. (1968) Optimal antibiotic therapy in cholera. Bull World Health Organ 39(2): 239-245.

126. Pierce NF, Banwell JG, Mitra RC, Caranasos GJ, Keimowitz RI, et al. (1968) Controlled comparison of tetracycline and furazolidone in cholera. Br Med J 3(5613): 277-280.

127. Bhattacharya SK, Bhattacharya MK, Dutta P, Dutta D, De SP, et al. (1990) Double-blind, randomized, controlled clinical trial of norfloxacin for cholera. Antimicrob Agents Chemother 34(5): 939940 .

128. Kabir I, Khan WA, Haider R, Mitra AK, Alam AN (1996) Erythromycin and trimethoprim-sulphamethoxazole in the treatment of cholera in children. J Diarrhoeal Dis Res 14(4): 243-247. 